\title{
Changes in the incidence and prevalence of rheumatoid arthritis in Kamitonda, Wakayama, Japan, 1965-1996
}

Kanji Shichikawa, Koji Inoue, Shigenaga Hirota, Akira Maeda, Hiroshi Ota, Masami Kimura, Toshio Ushiyama, Masaki Tsujimoto

\begin{abstract}
Objective-To evaluate secular trends in the incidence and prevalence of rheumatoid arthritis (RA) in Japan.

Methods-The incidence and prevalence of RA were determined in a longitudinal population based study in the Kamitonda district, Wakayama, Japan, from 1965 to 1996.

Results-In the study area consisting of about 3000 inhabitants, 16 incident cases, satisfying definite RA by the Rome criteria were detected during the study period. The age and sex adjusted incidence in both men and women combined and the age adjusted incidence in women significantly decreased $(p<0.025$ and $p<0.01$, respectively). The age and sex adjusted prevalence in all inhabitants tended to decrease $(p<0.1)$, and the age adjusted prevalence in women significantly declined $(p<0.025)$. In men, however, neither incidence nor prevalence showed significant change.

Conclusions-The decline of incidence and prevalence of female RA may be reducible to some environmental changes preferentially occurring more obviously in Japanese women than in men. Because the use of oral contraceptives has been extremely low in Japan, the decline should be explained by other factors.

(Ann Rheum Dis 1999;58:751-756)
\end{abstract}

Studies of the incidence of rheumatoid arthritis (RA) are rather few despite its importance, because of some inherent difficulties such as an uncertainty of diagnosis, the necessity of a prospective monitoring of a large population or an appropriate case collection, and many other variables implicated in prolonged periods of follow up. ${ }^{1}$ Reflecting the difficulties in conducting this kind of survey, different study methods have been applied, resulting in divergent incidence rates reported by varied authors. $^{2}$ Of the previous reports on this matter, community based studies are very few. ${ }^{3}$ Among them, one showed a secular declining of incidence of female RA over a 25 year period among Pima Indians in the USA. ${ }^{4}$ In general, as the methods are not similar, a direct comparison of the data does not seem to be always justified.

Regarding the Japanese population, there have been four studies on the incidence of RA, of which two were obtained from studies of atomic bomb survivors in Hiroshima and
Nagasaki, one in the period between 1958 and 1964, and the other between 1965 and $1966 .^{56}$ These studies, however, concerned a particular group of the population with short observation periods. The other two were conducted by our study group in the Tojo district between 1962 and $1966^{7}$ and in the Kamitonda district between 1965 and $1980 .{ }^{8}$

To overcome the methodological difficulties, we have been continuing to perform longitudinal community based surveys of RA over a long period in Kamitonda, a district in central Japan, applying consistent classification criteria and comparable survey methods. In this study, changes in the incidence and prevalence of RA in the population of Kamitonda during the period from 1965 to 1996 are reported.

\section{Methods}

The study was conducted from September 1965 to August 1996 in the Oka and Iwata areas of the Kamitonda district, Wakayama, Japan. The number of inhabitants living in the study area were approximately 3000 during the study period. At the beginning of the study, 70 per cent of the households depended primarily on agriculture for their income, but a gradual decreasing of the agricultural population has been observed for the subsequent period, with a slow increase in the number of inhabitants as a whole. The mobility of the study population has been very low. At the early phase of the survey, from 1965 to 1975 , the population increased from 2594 to 3045 , but thereafter remained nearly constant until 1988, and then showed a slight increase to 3150 by 1996 . The distribution by sex and age in the study population was similar to those of the general Japanese population, sharing a common trend of an increase of elderly persons and a decrease of children. The rate of inhabitants aged 65 or more to the whole study population increased from $12.1 \%$ in 1965 to $15.3 \%$ in 1992 . This aging trend, however, was less marked compared with that in the whole Japanese population (from $6.3 \%$ to $13.1 \%$ ).

The survey was performed approximately every four years (range, 3-5 years). In each survey, the following three consecutive procedures were performed for inhabitants of all age ranges; including children.

1 DISTRIBUTION OF QUESTIONNAIRE

Questionnaires concerning the constitution of family members including children, occupations, and rheumatic complaints were distributed by the town office to all households in the 


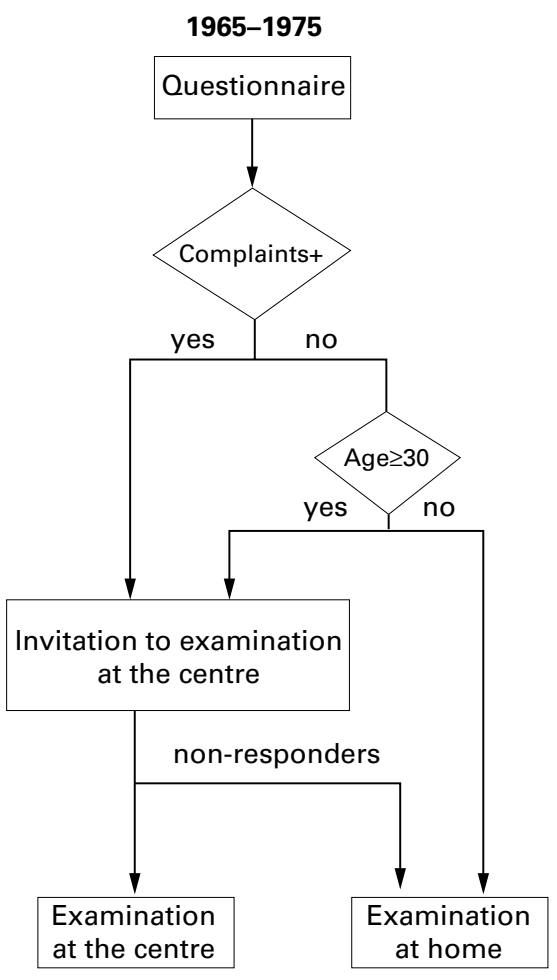

study areas. The questionnaires included present or past history of RA, morning stiffness, joint swelling, joint movement limitation, along with joint pain, neuralgia, low back pain, and others.

2 EXAMINATION AT THE CENTRE

Selected inhabitants, as described below, were invited to participate in a standardised examination at the community centre (the centre). After a medical history taking, a physical examination was performed. Peripheral joints and the spine were examined for the presence of tenderness, pain on passive motion, soft tissue swelling, restricted joint movement, and deformities. The presence of subcutaneous nodules, tophi, and rash were noted. Each examination was performed by several skilled orthopaedists who were experienced in rheumatic diseases. Blood was also taken for uric acid determination and serological tests, and radiographs were taken when necessary. Seropositivity was determined by the sensitised sheep cell agglutination test in an earlier period and, in a later period, the RA haemagglutination test, which used formalin and tannic acid treated sheep cells sensitised with heat treated rabbit Ig G.

\section{EXAMINATION AT HOME}

Those who did not undergo an examination at the centre were visited at home by several medical teams, each composed of a doctor who was competent in the field of rheumatology, a public health nurse, and an officer in charge of public health. After medical history taking, if a subject had any rheumatic complaints, a similar examination as described above was performed by a doctor. If necessary, blood tests
1980-1996

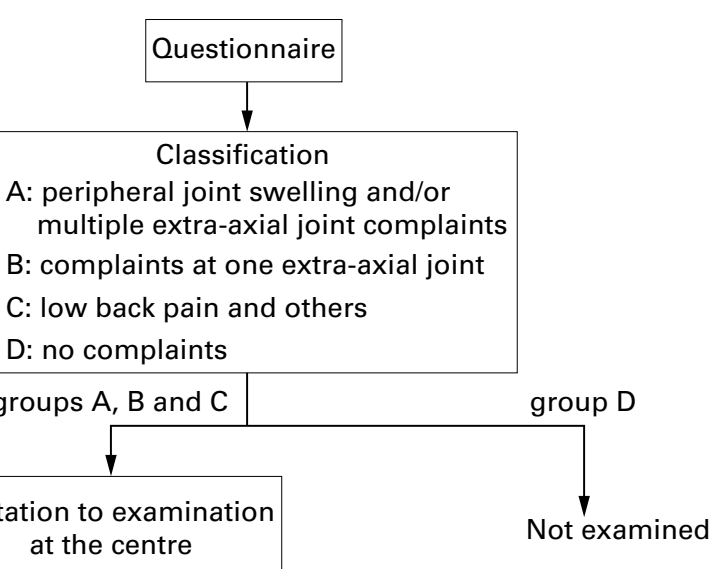
either at home or at the centre.

Throughout the whole study period, the three procedures were always performed. However, there were some modifications of the methodology during the study period (fig 1). From the first (1965) to the fourth survey (1975), every effort was made to examine all inhabitants either at the centre or at home. In these early surveys, not only those who stated any rheumatic complaints in the questionnaire but also all inhabitants aged 30 or more were invited to the examination at the centre for concomitantly performed epidemiological studies of osteoarthritis ${ }^{9}$ and sacroiliitis. ${ }^{10}$ After completing the examination at the centre, all households were visited by medical teams to examine those who were not invited to, or who did not respond to the examination at the centre.

Since the fifth survey in 1980 , the aim was focused on RA. Based on their questionnaire answers, inhabitants were classified into four groups (A, B, C and D). Group A subjects were those who had present or past complaints of peripheral joint swelling and/or present or past multiple extra-axial joint complaints. Group B subjects were those who had present or past complaints at one of the extra-axial joints. Group C subjects were those who had present or past rheumatic complaints, such as low back pain, which were irrelevant to any extra-axial joint symptoms. Those without any rheumatic complaints were classified into group D. All inhabitants, except for group D, were invited to the examination at the centre. Examination at home was subsequently performed for nonresponders who were invited to the examination at the centre. If group $A$ and $B$ non-responders could not be contacted at the 


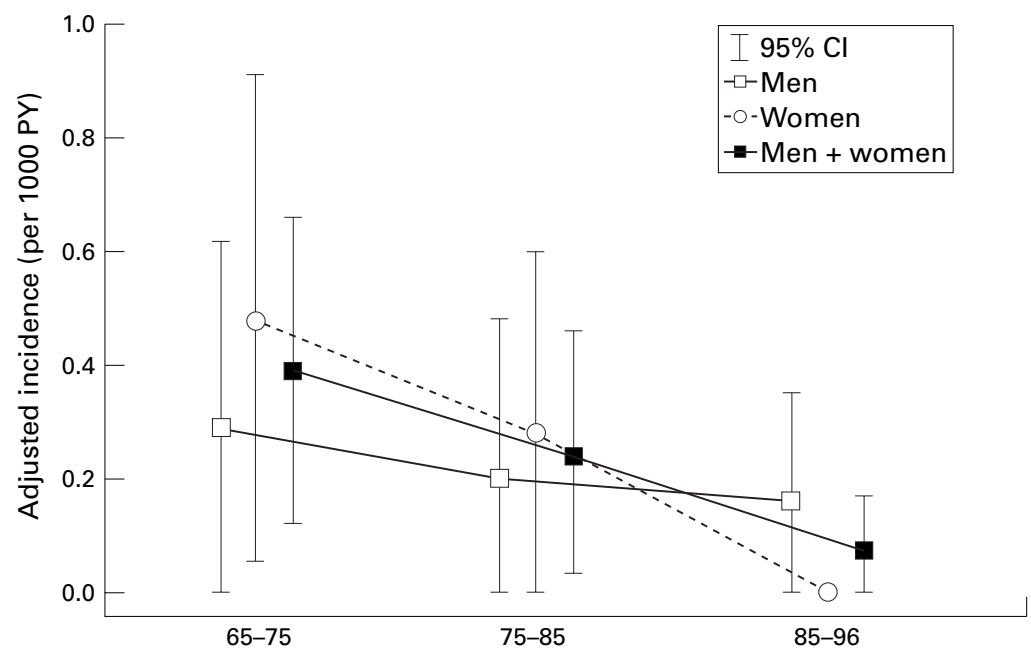

Figure 2 Changes of adjusted incidence.

first visit, they were revisited repetitively. Only in the fifth survey (1980) was the examination at home omitted for group B non-responders, as most of them had responded for the examination at the centre.

In the period from the first to the fourth surveys, the completion rate was defined as the number of inhabitants who underwent an examination at the centre or who were visited at home by a medical team divided by the number of total population, including children. However, in later surveys it was defined as the number of responders to the questionnaire divided by the number of total population, because almost all of the group A and B inhabitants were examined either at the centre or at home.

To assess those inhabitants with RA who could not be detected in our surveys, additional information on RA patients was provided from several sources. After the 1980 survey, a public health nurse in Kamitonda, who had been engaging in regular community surveys on chronic diseases designed by the Ministry of Public Welfare, provided a list of suspected RA cases. In 1980, additional information came from the national health insurance invoices issued by doctors in the district. In 1988,1992, and 1996, all general practitioners in the district provided information to us. After the

Table 1 Incidence of $R A$ in Kamitonda population during three time periods, 1965-1975, 1975-1985, and 1985-1996

\begin{tabular}{|c|c|c|c|c|}
\hline & $1965-1975$ & $1975-1985$ & 1985-1996 & trend \\
\hline \multicolumn{5}{|l|}{ Total } \\
\hline PY at risk & 22591 & 22832 & 32268 & \\
\hline Number of incident cases & 8 & 5 & 3 & \\
\hline Crude incidence ${ }^{\star}$ & 0.35 & 0.22 & 0.09 & \\
\hline $\begin{array}{l}\text { Adjusted incidence }{ }^{\star} † \ddagger \\
(95 \% \text { CI })\end{array}$ & $\begin{array}{l}0.39 \\
(0.12,0.66)\end{array}$ & $\begin{array}{l}0.24 \\
(0.03,0.46)\end{array}$ & $\begin{array}{l}0.08 \\
(0,0.17)\end{array}$ & $\mathrm{p}<0.025\left(\chi^{2}=5.77\right)$ \\
\hline \multicolumn{5}{|l|}{ Men } \\
\hline PY at risk & 10960 & 11090 & 15346 & \\
\hline Number of incident cases & 3 & 2 & 3 & \\
\hline Crude incidence ${ }^{\star}$ & 0.27 & 0.18 & 0.20 & \\
\hline Adjusted incidence ${ }^{\star} \dagger$ & 0.29 & 0.20 & 0.16 & $\mathrm{p}>0.5\left(\chi^{2}=0.44\right)$ \\
\hline \multicolumn{5}{|l|}{ Women } \\
\hline PY at risk & 11631 & 11742 & 16922 & \\
\hline Number of incident cases & 5 & 3 & 0 & \\
\hline Crude incidence ${ }^{\star}$ & 0.43 & 0.26 & 0.00 & \\
\hline $\begin{array}{l}\text { Adjusted incidence }{ }^{\star} \dagger \\
(95 \% \mathrm{CI})\end{array}$ & $\begin{array}{l}0.48 \\
(0.06,0.91)\end{array}$ & $\begin{array}{l}0.28 \\
(0,0.60)\end{array}$ & $\begin{array}{l}0.00 \\
(\mathrm{NC})\end{array}$ & $\mathrm{p}<0.01\left(\chi^{2}=7.44\right)$ \\
\hline
\end{tabular}

* per 1000PY, fadjusted for age, ładjusted for age and sex, CI: confidence intervals, NC: not calculated.
1996 survey, two major hospitals, serving the nearby population, including the study area, provided a list of RA patients to us.

The ARA criteria used for the diagnosis of RA was the 1961 Rome criteria as proposed by the Council for International Organization of Medical Sciences. ${ }^{11}$ Subjects who met the criteria for definite or classic RA were regarded as RA cases. Subjects who were at any time diagnosed as having probable $\mathrm{RA}$, and later as definite RA, were regarded as incident cases at the survey in which they first met the criteria for definite RA. The diagnosis of RA was always performed by a senior author throughout the entire study period. At each survey, previously detected RA cases were followed up by the same senior author, as long as they were living in the study area. The point prevalence rate of RA was calculated for each survey. To assess the linear trend of incidence, the whole study period was divided into three; 19651975,1975-1985, and 1985-1996. Person years at risk were counted only for the time during which subjects lived in the study area, and for those who responded to at least two surveys in the given period. Person years at risk within each period were calculated from the earliest survey to which one responded to the date of the survey in which one first met the criteria for definite RA, or for those without RA to the date of the latest survey to which one responded in the given period. Once a subject was diagnosed as having definite RA, he or she was not considered to be at risk in the later period, even when the disease remitted.

Incidence and prevalence rates were standardised for age or for both age and sex using the 1985 Census population of Japan. ${ }^{12}$ Age was stratified into eight categories: 0 to 14,15 to 24,25 to 34,35 to 44,45 to 54,55 to 64,65 to 74 , and 75 or more. The significance of linear trends in RA incidence and prevalence rates were tested using the Mantel-Haenszel extension of the $\chi^{2}$ test, ${ }^{13}$ controlling for age and sex.

\section{Results}

Completion rates for all nine surveys during the study period ranged from $75 \%$ to $97 \%$ with the average being $85 \%$. Between 1980 and 1996, the proportion of group A subjects in the entire responders to questionnaire ranged from $3.2 \%$ to $5.1 \%$ (mean $3.9 \%$ ) and group B subjects from $4.4 \%$ to $7.1 \%$ (mean $5.8 \%$ ). Almost all group A (99\%-100\%, mean $99.8 \%)$ and B subjects (95\%-100\%, mean $98.0 \%)$ underwent an examination either at the centre or at home.

There were 16 incident cases $(8$ men and 8 women) during the study period. As table 1 shows, the crude incidence rates for the total population were 0.35 per 1000 person years (PY) between 1965 and 1975, 0.22 between 1975 and 1985, and 0.09 between 1985 and 1996, for men $0.27,0.18$, and 0.20 , and for women 0.43, 0.26, and 0.00. Age and sex adjusted incidence rates during those three time periods for the total population were $0.39,0.24$, and 0.08 per 1000 PY. Age adjusted incidence rates for men were 0.29 , 0.20 , and 0.16 , and for women $0.48,0.28$, and 
Table 2 Point prevalence rate of $R A$ in nine consecutive surveys of the Kamitonda population

\begin{tabular}{|c|c|c|c|c|c|c|c|c|c|c|}
\hline & 1965 & 1969 & 1972 & 1975 & 1980 & 1985 & 1988 & 1992 & 1996 & trend \\
\hline \multicolumn{11}{|l|}{ Total } \\
\hline Number of RA cases & 5 & 10 & 7 & 7 & 8 & 9 & 6 & 6 & 6 & \\
\hline Crude prevalence ${ }^{\star}$ & 2.1 & 4.7 & 3.1 & 3.0 & 3.5 & 3.5 & 2.1 & 2.1 & 2.0 & \\
\hline Adjusted prevalence ${ }^{\star} \ddagger$ & 2.4 & 5.4 & 3.7 & 3.4 & 3.7 & 3.2 & 2.0 & 2.0 & 1.7 & $\mathrm{p}<0.1\left(\chi^{2}=3.58\right)$ \\
\hline \multicolumn{11}{|l|}{ Men } \\
\hline Number of RA cases & 0 & 2 & 2 & 1 & 2 & 3 & 2 & 3 & 2 & \\
\hline Crude prevalence $^{\star}$ & 0.0 & 2.0 & 1.8 & 0.9 & 1.8 & 2.4 & 1.5 & 2.2 & 1.4 & \\
\hline $\begin{array}{l}\text { Adjusted prevalence }{ }^{\star} \dagger \\
(95 \% \mathrm{CI})\end{array}$ & $\begin{array}{l}0.0 \\
(\mathrm{NC})\end{array}$ & $\begin{array}{l}2.5 \\
(0,6.0)\end{array}$ & $\begin{array}{l}2.3 \\
(0,5.5)\end{array}$ & $\begin{array}{l}1.1 \\
(0,3.4)\end{array}$ & $\begin{array}{l}2.2 \\
(0,5.3)\end{array}$ & $\begin{array}{l}2.0 \\
(0,4.3)\end{array}$ & $\begin{array}{l}1.1 \\
(0,2.7)\end{array}$ & $\begin{array}{l}1.7 \\
(0,3.6)\end{array}$ & $\begin{array}{l}1.1 \\
(0,2.6)\end{array}$ & $\mathrm{p}>0.5\left(\chi^{2}=0.13\right)$ \\
\hline \multicolumn{11}{|l|}{ Women } \\
\hline Number of RA cases & 5 & 8 & 5 & 6 & 6 & 6 & 4 & 3 & 4 & \\
\hline Crude prevalence ${ }^{\star}$ & 4.3 & 7.0 & 4.3 & 5.1 & 5.1 & 4.5 & 2.7 & 2.0 & 2.5 & \\
\hline $\begin{array}{l}\text { Adjusted prevalence }{ }^{\star} \dagger \\
(95 \% \text { CI })\end{array}$ & $\begin{array}{l}4.6 \\
(0.6,8.7)\end{array}$ & $\begin{array}{l}8.2 \\
(2.5,13.8)\end{array}$ & $\begin{array}{l}5.1 \\
(0.6,9.5)\end{array}$ & $\begin{array}{l}5.7 \\
(1.1,10.2)\end{array}$ & $\begin{array}{l}5.1 \\
(0.9,9.2)\end{array}$ & $\begin{array}{l}4.4 \\
(0.8,7.9)\end{array}$ & $\begin{array}{l}2.8 \\
(0,5.6)\end{array}$ & $\begin{array}{l}2.3 \\
(0,4.8)\end{array}$ & $\begin{array}{l}2.4 \\
(0.1,4.7)\end{array}$ & $\mathrm{p}<0.025\left(\chi^{2}=5.92\right)$ \\
\hline
\end{tabular}

${ }^{\star}$ per 1000 persons, fadjusted for age, ładjusted for age and sex, CI: confidence intervals, NC: not calculated.

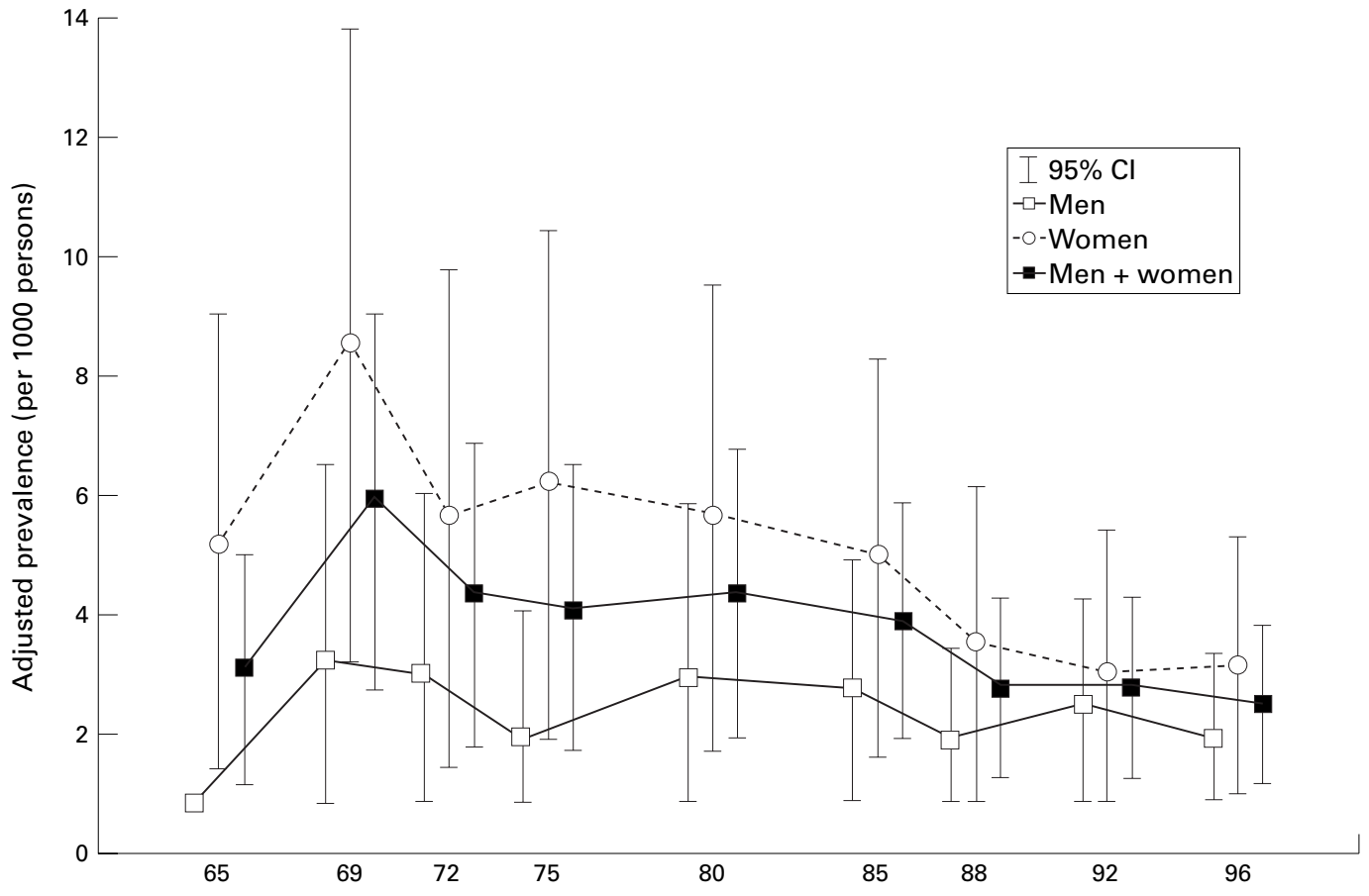

Figure 3 Changes of adjusted prevalence.

0.00 , respectively. The adjusted incidence significantly decreased during the study period for the total population $(p<0.025)$ and women $(\mathrm{p}<0.01)$, whereas no significant change could be seen for men $(p>0.5)$ (fig 2$)$.

Four cases ( 2 men and 2 women) out of 16 incident cases, diagnosed at least once as having definite RA, were apparently found to be completely remitted during the follow up examinations. Among these four cases, one always showed seronegativity, while in the other three, seropositivity fluctuated. However, they showed seronegativity at least once during the observation period, whereas the remaining 12 cases were always seropositive, suggesting a strong correlation between seronegativity and a benign course of RA. These four remitted cases were also non-erosive at the time of diagnosis. Later, one (woman) showed erosive change, 21 years after the diagnosis, without meeting the criteria for definite RA, and the other (man) became erosive 17 years after the diagnosis, fulfilling the criteria. The remaining two remitted cases (one man and one woman) continued to be non-erosive during the follow up period without fulfilling the criteria.
Table 2 shows the point prevalence rates of RA in nine consecutive surveys during the study period. The crude prevalence rates for both men and women combined varied from 2.0 to 4.7 per 1000 persons, for men from 0.0 to 2.4 , and for women from 2.0 to 7.0. Age and sex adjusted prevalence rates for both men and women combined varied from 1.7 to 5.4 , while age adjusted prevalence rates for men were from 0.0 to 2.5 , and for women from 2.3 to 8.2. The adjusted prevalence rate tended to decrease for both men and women combined $(p<0.1)$, and showed a significant decline for women $(p<0.025)$, whereas for men no significant change was observed $(p>0.5)$ (fig 3).

Additional information on RA patients was provided from a public health nurse, national health insurance invoices, general practitioners, and hospitals. However, no additional cases were found in the study population from these sources.

\section{Discussion}

During a 31 year study period of the Kamitonda population, there was a decrease in 
the incidence of RA in the whole population, which was confined to women. A decrease of prevalence was also evident for the whole population, which was also restricted to women, reflecting the decrease of incidence in women.

Until now, four studies have reported the incidence of RA in Japan. Each was community based and performed from the late 1950s to 1970s. Two were successively performed on atomic bomb survivors in Hiroshima and Nagasaki, and showed the crude incidence of definite RA to be 0.4 per 1000 PY for all ages in the first 1958-1964 survey and 0.9 per 1000 PY in the second 1965-1966 survey. ${ }^{56}$ The third, conducted by our study group in the Tojo district, Tondabayashi, Osaka from 1962 to 1966 , estimated the crude incidence of definite RA in inhabitants of all ages to be 0.6 per $1000 \mathrm{PY}^{7}$ The fourth was the early results of the present Kamitonda study from 1965 to $1980,{ }^{8}$ in which the incidence of both probable and definite RA combined were described. Hence, subjects with probable RA at the first survey in 1965 who later met criteria for definite RA were not regarded as incident cases in our previous report, being different from the present report. As seen in this study, the crude incidence of definite RA in Kamitonda between 1965 and 1975 was 0.35 per 1000 PY, being within an expected range in Japan at that time. The incidence of RA in Kamitonda is probably representative of the whole population of Japan. In addition, the figures are similar to those obtained by recent studies in white populations. They were 0.4 in the $\mathrm{UK}^{1}$ and 0.37 in Finland, ${ }^{14}$ although the survey methods were quite different, the former being based on a prospective case notification and the latter on records review.

Secular changes in the incidence of RA have been suggested in several reports. Of these, Linos et al,,$^{15}$ Dugowson et al, ${ }^{16}$ and Hochberg ${ }^{17}$ recognised a declining trend only in women, whereas Chan et $a l^{18}$ concluded from a three year observation that there was no secular change in incidence. On the other hand, Kaipiainen-Seppanen et $a l^{19}$ observed an approximately $15 \%$ decline in the incidence of RA from 1980 to 1990 , affecting seronegative RA nearly exclusively, particularly in men. These studies were mostly based on records from hospitals and general practitioners, or members of a specified group, with the inevitable selection bias ensuing. In only one report, by Jacobsson et $a l,{ }^{4}$ incidence and its secular decline in women was shown by a community based approach, but it was from a group of Pima Indians, a particular population having unusually high seropositivity and a much higher incidence rate than found in white populations.

Even in a community based study like ours, the problem of selection bias may be encountered during the long term follow up period. In this study, selection bias may have been introduced by modification of the survey method, being obliged to do so for a variety of reasons. In the earlier period from 1965 to 1975 , every effort was made to examine all inhabitants, either at the centre or at home, regardless of rheumatic complaints, because the study was being performed not only for RA but also for other rheumatic diseases. In the later period from 1980 to 1996 , examination at the centre or at home was restricted to those who had rheumatic complaints. We believe, nevertheless, that this modification did not influence our results. Firstly, there were no incident cases who seemed to have gone undetected in the preceding surveys. Secondly, the decline of incidence was only observed in women, while the incidence of men remained much the same throughout the study period. Thirdly, a decline of incidence for women was also noted from the second to the third period. Fourthly, the information provided from several sources did not add any new cases who were not found by our surveys. The size and low mobility of the study population enabled us to gather adequate long term information on the health status of the inhabitants.

As is always the case of a longitudinal population based study of RA, subjects with a benign form of RA whose symptoms were transient and relapsing could have been missed. ${ }^{20}$ As our evaluation of inhabitants was made at survey intervals of 3-5 years, patients with RA in whom onset and remission occurred between two consecutive surveys may have been ignored. However, we consider this possibility to be very low, because we did not encounter any person with such history throughout all of the surveys. Furthermore, we did not find any relapsed case of RA who may have escaped detection previously. The completion rates in our surveys were high and subjects with a past history of arthritis or rheumatic complaints possibly related to RA were all interviewed by doctors. Nevertheless, the possibility of missing mild cases could not be completely neglected, but would be minimised by the prolonged observation of the same population.

In a longitudinal observation of incident cases, four of 16 cases later showed complete remission. One of them fulfilled the criteria again in 1992, 17 years after the initial diagnosis of RA. We did not consider this person as a new case in 1992. Whether we had counted this case as new or not, does not influence the nature of our results, as this relapsed case was male. We further tested how the results would change, assuming that one more woman with RA had been found during 1985-1996. However, the trend of declining incidence of total population $\left(\chi^{2}=4.20-4.42\right)$ and of female RA $\left(\chi^{2}=4.78-5.12\right)$ still remained significant with the statistical power of $\mathrm{p}<0.05$, regardless of the age of the postulated woman.

The decline of incidence of RA in Kamitonda may be explained by a change of some environmental factors preferentially occurring more obviously in women. Linos et al, ${ }^{15}$ recognising the declining incidence of female RA, suggested that the use of oral contraceptives was responsible, whereas Jacobsson et $a l^{4}$ argued against the supposition that use of oral contraceptives could explain the declining incidence, as the use of such pills was constant in 
the Pima Indian population during the survey period. It should be noted that, in Japan, oral contraceptives have not been available on the free market, but only when a doctor recognised their necessity and prescribed them. Therefore, the use of these drugs has invariably been very low in our country, at approximately $1 \%$ of total contraception. ${ }^{21}$ The very low rate of current or ever oral contraceptive users in population was also confirmed in our previous report. ${ }^{22}$ Accordingly, the use of oral contraceptives cannot be a responsible factor for the observed phenomenon in our country. The most marked changes occurring in Japanese women in the past years are seen in social factors, of which we can enumerate the following; an increase of economic independence, a higher educational level, and a marked decrease in the birth rate, thus facilitating employment and social activities. These phenomena are apparently in accordance with the hypothesis by James who stated that a higher androgen concentration in women responding to an augmented role in the society could prevent the onset of RA. ${ }^{23}$

The rather unusual finding that the cumulative incidence was almost the same in men and women might also argue that the onset of RA is more dependent on external life conditions in women than in men, as suggested above. On the other hand, three of 16 incident cases (19\%) had an occurrence of RA in first degree relatives. Interestingly, all three incident cases with familial occurrence were in men. According to Kwoh et $a l,^{24}$ in cases with multiple familial occurrence of RA, the female to male ratio for probands was $1: 1$ versus $3: 1$ in cases with single familial occurrence. Therefore we speculate that although the number of patients is very small, RA in men might have been seen more often in genetically disposed persons, thus revealing the constant incident rate of RA in men. As a result, the occurrence of RA may in the future become nearly equal between sexes.

It is worthy to note, however, that our report concerns the significant declining tendency of incidence of RA in Japanese women, as obtained from community based follow up surveys covering a period of more than 30 years. Nevertheless, as it is based on an obviously small number of incident cases, the extent of our conclusions is limited, as seen by the fairly broad confidence interval of the incident density estimate.

We are grateful to the late Drs Tozo Kashiwade and Ichiro Hongo, and the many doctors in Osaka University Medical School and Shiga University of Medical Science who collaborated with us in carrying out this study. We profoundly appreciate the continued help of the public nurses, Toshiko Yamada and Michiyo Takagaki, as well as the previous and present headmen and staff of the Kamitonda town office, without whom this study could not have been possible. We wish to acknowledge the friendly cooperation of the Hospital for Disabled, Wakayama National Hospital, Kinan Hospital, and the general practitioners in or around the study area. We are also grateful to Professor Hirotsugu Ueshima in Shiga University of Medical Science who kindly provided technical information on statistical analyses. Funding: this study was supported in part by a grant in aid for Scientific Research from the Ministry of Education, Science and Culture of Japan and by a grant from the Ministry of Health and Welfare of Japan.

1 Symmons DPM, Barrett EM, Bankhead CR, Scott DGI, Silman AJ. The incidence of rheumatoid arthritis in the United Kingdom:results from the Norfolk arthritis register. Br J Rheumatol 1994;33:735-9.

2 Silman AJ, Hochberg MC. Epidemiology of the rheumatic diseases. Oxford: Oxford University Press, 1993.

3 Abdel-Nasser AM, Rasker JJ, Valkenburg HA. Epidemiological and clinical aspects relating to the variability of rheumatoid arthritis. Semin Arthritis Rheum 1997;27: rheumatoid

4 Jacobsson LTH, Hanson RL, Knowler WC, Pillemer S, Pettitt DJ, Mc Cance DR, et al. Decreasing incidence and prevalence of rheumatoid arthritis in Pima Indians over a twenty-five-year period. Arthritis Rheum 1994;37:115865.

5 Wood JW, Kato H, Johnson KG, Uda Y, Russell WJ, Duff IF. Rheumatoid arthritis in Hiroshima and Nagasaki, Japan: prevalence, incidence and clinical characteristics. Arthritis Rheum 1967;10:21-31.

6 Kato H, Duff IF, Russell WJ, Uda Y, Hamiltom HB, Kawamoto S. Rheumatoid arthritis and gout in Hiroshima and Nagasaki, Japan: a prevelence and incidence study. J Chron Dis 1971;23:659-79.

7 Shichikawa K. Prevalence of rheumatic diseases in Japan. In: Shichikawa K. Prevalence of rheumatic diseases in Japan. In:
Bennett PH, Wood PHN, eds. Population studies of the rheumatic siseases. Amsterdam: Excerpta Medica, 1968:55-9.

8 Shichikawa K, Takenaka Y, Maeda A, Yoshino R, Tsujimoto $\mathrm{M}$, Ota $\mathrm{H}$, et al. A longitudinal population survey of rheumatiod arthritis in a rural district in Wakayama. Ryumachi 1981;21 (suppl): 35-43

9 Ota H. Prevalence of osteoarthrosis of the hip and other joints in Japanese population [in Japanese]. J Jpn Orthop Assoc 1979;53:165-80.

10 Shichikawa K. Ankylosing spondylitis [in Japanese]. Ryumachi 1976;16:395-407.

11 Kellgren JH, Jeffrey MR, Ball JF, eds. The epidemiology of chronic rheumatism. Oxford: Blackwell Scientific Publications, 1963.

12 Statistic Bureau, Management and Coordination Agency of Japanese Government. fapan Statistical Year Book [in fapanese]. 41 st ed. Tokyo: Japan Statistical Association, 1991.

13 Mantel N. Chi-square tests with one degree of freedom: extension of the Mantel-Haenszel procedure. Journal of the American Statistical Association 1963;58:690-700.

14 Aho K, Kaipiainen-Seppanen O, Heliovaara M, Klaukka T Epidemiology of rheumatoid arthritis in Finland. Semin Arthritis Rheum 1998;27:325-34.

15 Linos A, Worthington JW, O'Fallon WM, Kurland LT. The epidemiology of rheumatoid arthritis in Rochester, Minnesota: a study of incidence, prevalence, and mortality. Minnesota: a study of incidence, prev

16 Dugowson CE, Koepsell TD, Voigt LF, Bley L, Nelson JL, Daling JR. Rheumatoid arthritis in women: incidence rates in group health cooperative, Seattle, Washington, 1987 1989. Arthritis Rheum 1991;34:1502-7.

17 Hochberg MC. Changes in the incidence and prevalence of rheumatoid arthritis in England and Wales, 1970-1982. Semin Arthritis Rheum 1990;19:294-302.

18 Chan KA, Felson DT, Yood RA, Walker AM. Incidence of rheumatoid arthrritis in central Massachussets. Arthritis Rheum 1993;36:1691-6.

19 Kapiainen-Seppanen O, Aho K, Isomaki H, Laakso M. Incidence of rheumatoid arthritis in Finland during 19801990. Ann Rheum Dis 1996;55:608-11.

20 MacGregor AJ, Ailman AJ. A reappraisal of the measurement of disease occurrence in rheumatoid arthritis. J Rheumatol 1992;19:1163-4.

21 Kuwabara Y. Present status of oral contraceptive pills in Japan [in Japanese]. Nihon Ishikai Zasshi 1992;108:573-6.

22 Inoue K, Ushiyama T, Kim Y, Shichikawa K, Nishioka J, Hukuda S. Increased rate of hysterectomy in women undergoing surgery for osteoarthritis of the knee. Osteoarthritis Cartilage 1995;3:205-9.

23 James WH. Rheumatoid arthritis, the contraceptive pill, and androgens. Ann Rheum Dis 1993;52:470-4.

24 Kwoh CK, Venglish C, Lynn AH, Whitley DM, Young E, Chakravarti A. Age, sex, and the familial risk of rheumatoid arthritis. Am J Epidemiol 1996;144:15-24. 